\title{
MENSAGEM À USP FILARMÔNICA
}

\author{
Alysson Leandro Mascaro \\ Universidade de São Paulo \\ alysson@mascaro.adv.br
}

Ao amigo Maestro Rubens Russomanno Ricciardi.

Ao corpo docente, discente e musical da USP Filarmônica.

\section{Resumo}

São dois os campos de reflexão necessários para um pensamento material, radical e consequente sobre a relação entre música e sociedade. $\bigcirc$ primeiro deles, o da determinação social da música. $\bigcirc$ segundo deles, o do papel político da música e também do músico. Aponto aqui, filosoficamente, para estas duas problemáticas, suas bases estruturais e suas consequências políticas.

Palavras-Chave: Música e sociedade; subjetivismo; objetivismo; Karl Marx.

\section{A determinação social da música}

Na investigação sobre música e sociedade, há quatro possíveis e distintas chaves de explicação: dissociação (o gênio); acoplamento subjetivo (o politicismo musical); acoplamento objetivo (o economicismo musical); determinação (a reprodução social na totalidade estruturada). A primeira das chaves explicativas, a dissociação, propõe a arte como distinta da reprodução social. As três outras chaves contrastam com esta primeira, mas duas das três recaem em acentos parciais da relação entre música e sociedade. Somente a última - e mais alta - das chaves abre a possibilidade de um pensamento consequente e material sobre tal relação. 
A dissociação entre música e sociedade é o padrão explicativo do pensamento conservador, institucional, com laivos reacionários, e que foi clerical na ldade Média, nobre na ldade Moderna e é burguês na ldade Contemporânea. Desponta aqui a noção do gênio. A arte é tomada como excepcional e o músico - compositor ou executor - é superior e contrastante com seu tempo, genial portanto. Tal consideração a respeito da excepcionalidade engendra a hierarquia social, o corte, a distinção: o produtor musical e seu produto são valiosos, dado que luxuosos e raros, em geral reputados feitos sem prévios mestres, agraciados pelo dom. $\bigcirc$ gênio distingue também seus mecenas e seus consumidores, os estamentos nobres e/ou as classes dos proprietários dos meios de produção. Leituras da dissociação entre música e sociedade são via de regra conservadoras, quando produção e consumo musical estão no mesmo tempo histórico (classicistas no século XVIII, românticos no século XIX), ou são reacionárias, quando o passado retoma ou na produção ou no consumo ou em ambas as esferas (neoclassicistas ou neorromânticos a partir de meados do século XX).

Duas outras chaves de leitura pretendem-se "neutras" ou de "bom senso". Propõem que haja relação entre música e sociedade, portanto uma historicidade, mas que ela tenha por explicação apenas um grupo de fatores. Decorre, dessa parcialidade, sua incapacidade de alcançar uma plena cientificidade a respeito. A primeira delas é a explicação do subjetivismo. Em tal perspectiva, reconhece-se que a produção, a execução e a audição da música são feitos histórica e socialmente, mas, ao mesmo tempo, há um espaço da criação, da reprodução e do consumo que é próprio dos seus sujeitos agentes ou pacientes. Há uma historicidade da música em variadas fases, mas a criação é feita a partir de tal base, não por causa ou por coerção direta dela. Tratase de uma mitigação da leitura do gênio. Parodiando o velho ditado, todo músico romântico opera nos tempos burgueses, mas nem todos eles são Richard Wagner. Trata-se de um "bom-senso" subjetivista. A vontade do criador, do executor ou do consumidor eleva-se do seu tempo para além dele. Daí o voluntarismo é sua categoria filosófica, política, psíquica e sociológica. Pelo querer subjetivo, seria possivel corrigir deficiências musicais, inapropriações históricas, anacronismos. Trata-se de uma acepção centrada na categoria de "gosto", tomado no sentido da vontade estética liberal, sendo esta fundada na liberdade de escolha dos sujeitos. Decorrem, disso, postulações liberais como a de bom-gosto, melhoria estética, educação musical. Os problemas musicais não estão nas estruturas sociais e em sua reprodução: por essa leitura, há problema 
nos sujeitos e na sua ausência de vontade, lapidação ou educação. Os que assim quiserem se aperfeiçoam, e tal incremento acaba por ser, por fim, a manutenção da hierarquia e da distinção entre classes, grupos e indivíduos. $\bigcirc$ subjetivismo na compreensão da relação entre música e sociedade é uma espécie de "meritocracia” musical.

A outra chave de explicação parcial sobre a relação entre música e sociedade é a do objetivismo. Trata-se do oposto da visão anterior. A música não é obra de gênio nem da mera vontade dos sujeitos. Há objetividades que a explicam. A economia e a política revelam a economia e a política da música, de tal sorte que se compreenderia, com isso, o porquê da persistência de neoclassicismos e neorromantismos em pleno século XXI - a desorganização produtiva do capitalismo e sua financeirização fazem com que a música seja pósmoderna ou de embuste. Músicos e consumidores não são meros sujeitos de sua vontade, mas sujeitos em historicidades objetivas. A música não é um capricho ou um voluntarismo, mas um reflexo da objetividade. Há uma indústria cultural, de tal sorte que se pode, contra esse complexo objetivo, apontar programa, dar sentido, lutar por um desenvolvimento social. Os nacionalismos em cada país periférico dos séculos XIX e XX, o realismo socialista, a criação de mitos musicais - glórias nacionais como Carlos Comes no Brasil - são movimentos que buscam intervir na relação entre música e sociedade no plano da objetividade.

Acerca da relação entre música e sociedade, acuso a explicação subjetiva de politicismo; acuso a explicação objetiva de economicismo. A primeira das visões crê que se possa empreender, por meio da educação dos indivíduos, uma música melhor. A segunda das visões reconhece que não se trata de questão de gosto, mas de objetividades sociais que devem ser desenvolvidas. Neste economicismo desponta a noção de plano objetivo, planejamento, progresso social, desenvolvimentismo. $\bigcirc$ politicismo é, na música, o encaminhamento político do liberalismo burguês, desde o século XIX até o neoliberalismo do final do século XX e início do século XXI. O economicismo é, na música, o encaminhamento político do desenvolvimentismo, do keynesianismo, do planejamento de capitalismo intervencionista, que foi típico de países capitalistas e de experiências como as soviéticas. Ocorre que economicismo e politicismo se intercambiam constantemente no fracasso de suas parcialidades, porque são plataformas distintas de uma mesma sociabilidade capitalista. Daí, o fracasso de grandes saltos economicistas busca se socorrer de esforços de guerra que reclamam a vontade. Na música,

\section{5}

REV. TULHA, RIBEIRÃO PRETO, v. 6, n. 2, pp. -, jul.-dez. 2020 
envolve proteger objetivamente nomes subjetivamente valiosos - salvar a biografia inatacável de Tchaikovsky como parte da glória russa; louvar Khachaturian como símbolo da Armênia que pode ser reconhecida mundialmente. No outro lado da moeda, o fracasso do subjetivismo liberal se socorre de economicismos explicativos - porque não há investimento nem mecenas, não há grandes músicos hoje como José Maurício, Carlos Comes e Villa-Lobos o foram para o Reino, o Império e o varguismo. Decorre disso que o mérito individual que não brota se socorre da culpa do Estado que sufoca ou não apoia. Politicismo (voluntarismo) e economicismo (determinismo) são sempre os dois polos - antípodas e ao mesmo tempo complementares - das explicações parciais capitalistas sobre o problema social da música.

Destaca-se então, no seio de tais possiveis chaves de leitura, a explicação científica, consequente e materialista sobre a relação entre música e sociedade. Trata-se de encontrar não a vontade musical contra a sociedade ou um determinismo, mas sim as determinações sociais especificas que operam suas relações. Há determinação social, cuja compreensão científica tornou-se possivel a partir da obra de Karl Marx. Em sociedades sob modo de produção capitalista, as relações sociais tomam forma de exploração assalariada, fazendo com que tudo e todos se perfilhem numa imensa coleção de mercadorias, sendo estas o átomo da sociabilidade e sendo a acumulação sua lei geral. A música opera relacionalmente nesse quadro, com determinações que se fazem pelos sujeitos da produção e do consumo musical. Quando se diz que no capitalismo a música é capitalista, isto se dá não necessariamente pelo gosto musical ou pela ideologia de quem a produz ou consome, mas porque os meios relacionais da música só podem se dar pelas formas de sociabilidade capitalista. Formação e educação de músicos, aquisição e disponibilidade de instrumentos musicais, empregos, salários e meios de vida, patrocínios, eventos, gravações, edições, todo esse complexo é da mercadoria. A música está mergulhada, enquanto relação social, nas próprias formas da sociabilidade. Ocorre que, sendo arte e, portanto, produção, ela é empreendida por sujeitos que são determinados pelo capitalismo por dispositivos materiais e práticos de constituição da subjetividade, como os aparelhos ideológicos. Assim, são os sujeitos - insignemente, especificamente - que produzem, executam, ouvem e criticam a música, de tal sorte que não se possa falar de um objetivismo não-relacional ou de um determinismo social. Há sujeitos da música, há suas práticas e estratégias relacionais múltiplas. Mas tais sujeitos são 
objetivamente determinados por formas relacionais. Trata-se de uma dialética que faz com que o objetivo se forje pelo subjetivo e vice-versa.

capitalismo é uma miríade de sujeitos distintos, mas essas várias subjetividades estão erigidas pelas mesmas interações sociais. Cidadãos, sujeitos de direito, que dispõem da vontade contratualmente, possuindo ou não meios de produção. Tais sujeitos são múltiplos e, ao mesmo tempo, são todos assujeitados pelo capital, distinguindo-se então por classes, grupos, explorações e opressões várias. Para lembrar Mario de Andrade, é possivel conclamar ou não para que sejamos todos musicais, mas tal conclame à subjetividade se perfaz por relações sociais objetivas: condições de acesso determinadas nos níveis econômico, político, educacional, religioso, cultural, valorativo. É mais que apenas um querer ser musical subjetivamente. $\bigcirc$ capitalismo e o feudalismo operam como modos de produção de compulsória posição de classe dos sujeitos. Não se é servo ou assalariado por vontade, mas é pela vontade que, no capitalismo, alguém se submete a alguém para receber seu salário. Também é pela vontade que um músico se faz, mas não é pela sua vontade que suas condições se dão.

No capitalismo, operam específicas objetividades materiais. Elas têm por núcleo as determinações econômicas, derivando, também, numa forma política específica, estatal. Assim, todas as coisas, e também a música, são tornadas mercadorias e são atravessadas pela acumulação. Com o fim das sociedades estamentais, de castas, definha a música clássica e a crescente burguesia - que deverá desejar, voluntariamente, pagar para consumir música - é sensibilizada por um tipo musical aliciante pelo gosto, o romantismo. A repetibilidade, a emoção, o arrebatamento e a surpresa passam a ser dispositivos musicais centrais. Tal processo constitui o chão e também o teto da música clássica (aqui tomada por sinédoque): ela é produto de sociedades mercantis, que lhe dão a base, mas também têm por teto a própria mercantilização dessas sociedades. Como há produtos musicais mais fácil ou reiteradamente consumidos - a música popular -, então a indústria cultural musical erudita ou clássica se erige como um nicho, tal qual o consumo de luxo em face do consumo de massas.

Mas tal processo capitalista tem, por seu derivado, uma forma política estatal, que opera nessa mesma seara de modo símile ou contraditório. Podem-se ver, no Estado, demandas políticas próprias - o nacionalismo, por exemplo - que o façam ser agente de vetorizações à

\section{7}

REV. TULHA, RIBEIRÃO PRETO, v. 6, n. 2, pp. -, jul.-dez. 2020 
música similares ou relativamente distintas daquelas do interesse burguês. É possivel que uma burguesia nacional do continente americano tenha gostos e laivos musicais europeus e o Estado tenha por estratégia política a valorização da música nacionalista. Vê-se, então, uma contradição entre o político e o econômico. Aqui, no entanto, trata-se de autonomia apenas relativa. Os Estados se financiam de modo capitalista, o que faz com que haja graus necessários de coesão com as burguesias. No plano musical, o acoplamento do político com o econômico na música se dá entre variadas posições dentro dos dois extremos do pêndulo: há tanto a pretensão estatal a vetorizar musicalmente a sociedade (nacionalismos, capitalismos de Estado ou manutenção da indústria cultural de países capitalistas centrais) quanto o louvor ideológico do liberalismo musical pelo consumo (o mercado da música se autorregularia).

Só se pode estabelecer cientificamente a relação entre música e sociedade se se tiver em mente as formas sociais determinantes da sociabilidade e, portanto, as relações sociais específicas possíveis da música. Por isso, a reflexão mais alta filosoficamente sobre a música não é aquela a respeito de seu conteúdo ou de seu afazer técnico, mas sim da sua condição relacional social estrutural. É daí que advém tanto a força da música quanto a força da crítica. Dizer que há relação de determinação da música pela sociedade é entender que a música se faz historicamente e que os impasses e as contradições da música são, relacional e estruturalmente, os problemas da sociedade. Havendo tal determinação complexa - nem voluntarismo nem determinismo -, então a música não é distinta ou o outro da sociedade, mas uma de suas manifestações. Decorre daí que pensar a música é fundamentalmente pensar a sociedade. Não se trata de uma implicação recíproca indiferente. A sociedade determina a música; esta não determina a sociedade. Então a música não é um refúgio seguro contra o mundo nem o cadinho de refundação da sociabilidade. $\bigcirc$ problema da música, no estrutural, é apenas uma das faces do problema da sociabilidade. 


\section{Música: que fazer?}

Proponho que a relação de determinação entre música e sociedade seja pensada, em termos de ação política, a partir de duas frentes: a política da música em face das formas sociais; a política da música em face das formações sociais. Na primeira das frentes, trata-se de pensar os termos gerais da música no capitalismo. Na segunda das frentes, pensa-se a música em sociedades capitalistas concretas, suas demandas, contradições, antagonismos e lutas em tempos históricos específicos.

complexo social da música - compositores, músicos, ouvintes, teóricos - se confronta com uma sociabilidade capitalista que, por suas formas, estabelece as coerções às relações sociais e as subjetividades. Os impasses do capitalismo são os mesmos para todos os músicos: sobrevivência dos trabalhadores da música a partir de remuneração salarial, bolsa ou mecenato; empregabilidade; circulação mercantil da música; mercado consumidor; concorrência e competitividade entre músicos; subjetividade do músico - narcisismo; descolamento do mercado produtivo geral. Ao mesmo tempo, o capitalismo estabeleceu - campo de atuação econômica e social da música clássica ou erudita: um nicho em face da música de massas, no seio da indústria cultural. Tais marcações e molduras são a conjugação das formas sociais capitalistas - tendo por átomo a forma mercadoria - com as formas sociais e estéticas da música clássica. No que tange às formas sociais da música, revelam-se aqui as coerções do tempo necessário de educação e preparação do músico, das instituições musicais como orquestras -, da carreira do músico. No que se refere às formas estéticas da música, as manifestações musicais se erigem em função do mercado e do consumo: gêneros musicais - concerto, sinfonia, ópera, sacro -; utilização de recursos humanos em face das disponibilidades econômicas (se orquestração sinfônica, filarmônica, de câmara ou solista); programa musical; extensão temporal da música; gosto musical conservador ou contestador etc. Neste sentido, erige-se um todo social determinante e coercitivo da relação entre as formas da música e as formas sociais.

Proponho que haja três caminhos da filosofia contemporânea e aplico tal proposta às possíveis leituras filosóficas do músico na contemporaneidade. As posições políticas do músico em face do todo das formas sociais e musicais podem se dar em três caminhos: de liberalismo 
ou pleno capitalismo (conformismo), de não-liberalismo (reacionarismo) e de crítica (transformação). No que tange ao conformismo, trata-se de se ajustar à indústria cultural. $\bigcirc$ músico formado em universidade, empregado em instituições musicais, compositor ou executante adequados ao gosto musical médio é seu perfil. É-lhe indiferente a forma musical, porque tem por pressuposto que a forma social - música como mercadoria a ser consumida - já está naturalizada: o capital sempre dará a sorte da música. No que se refere ao reacionarismo, seu acoplamento, via de regra, se dá por instituições que agem à margem do mercado do consumo musical. As religiões ou as instituições políticas e sociais estamentais, aqui, cumprem um papel decisivo. Em tais grupos, estamentos ou espaços, há uma autorreferência musical, distinta do gosto de mercado. Assim, as músicas de matriz teológica aos religiosos, de base marcial aos militares, de motivos folclóricos ou populares aos nacionalistas, são sustentadas pelos organismos estamentais, relativamente alheados do mercado e da indústria cultural. No terceiro dos caminhos que proponho, de crítica transformadora, a posição política do músico não se faz nem em apoio ao gosto de mercado, nem em retrocesso a nichos reacionários. A música é testada até seu limite. Há uma bifurcação interna neste campo da crítica transformadora. No primeiro de seus eixos, de centro-esquerda, reformista, vê-se na música um elemento educacional progressista às massas e, então, operando no positivo, crê-se numa forma musical relativamente aderente às massas (nacionalismo no Brasil, com Villa-Lobos, Camargo Guarnieri etc.; realismo socialista no campo soviético, como Shostakovich e Khachaturian etc.). Chamarei filosoficamente, a essa possibilidade, de crítica pela música. No segundo dos eixos, de crítica à própria forma musical e sua aderência às formas da sociabilidade, então se desdobra uma música de vanguarda ou inovação (num processo que na Europa se deu com Arnold Schoenberg, Alban Berg, Anton Webern, Pierre Boulez ou Karlheinz Stockhausen, e no Brasil teve por catalisador Hans-Joachim Koellreutter). Tal nova música, nos dizeres de Theodor Adorno, operando no negativo, alcança uma crítica à forma. Chamarei filosoficamente, a essa possibilidade, de crítica da música. Peculiarmente, no início do século XX, quando das demandas revolucionárias, a crítica à forma musical estava parelha da crítica da forma mercadoria. Com a resiliência e a manutenção do capitalismo até a atualidade, a crítica da forma musical, se feita apenas no ambiente interno dos músicos, desprovida do mesmo radicalismo no acoplamento com a crítica das formas sociais, acaba por ser uma dissociação olímpica das contradições do mundo

\section{0}

REV. TULHA, RIBEIRÃO PRETO, v. 6, n. 2, pp. -, jul.-dez. 2020 
e, portanto, uma ação impotente ou uma inação estrutural. Será apenas a revolução que dará sentido a uma nova crítica da música.

A segunda das frentes da política da música se refere à formação social. Aqui, enraízam-se as formas sociais do capitalismo e da música em sociedades historicamente específicas. Fala-se, então, dos problemas de sociedades concretas no espaço e no tempo: espacialmente, o Brasil, em contraste com outras formações sociais como as europeias; temporalmente, as sociedades do século XXI, de capitalismo pósfordista, em face do capitalismo fordista do século XX etc. Tratarei de dois eixos internos da formação social brasileira: os problemas advindos de seu passado; os problemas do presente. Sobre a determinação do passado no presente, a ação política do músico no Brasil tem que se confrontar com uma história específica da música na sociedade: colônia, escravismo, monarquia, estamentos que deslizam para ser classes, conservadorismos e reacionarismos reiterados e persistentes, tudo isso marca a música clássica ou erudita como distinção, marcador de superioridade social, sem um vivo mercado de produção, consumo e crítica. Daí, o músico, mesmo que progressista, via de regra trabalha para um público conservador, com ele se confronta e por ele é confrontado.

Tal história da formação social da música no Brasil se encontra, então, com sua situação e seus problemas presentes. $\bigcirc$ capitalismo brasileiro é zona de atrito do domínio do capitalismo mundial e de sua crise. Tentativas parciais de desenvolvimentismo e pujança dos tempos de política progressista brasileira de início do século XXI investimento em universidades públicas, financiamento de orquestras foram alijadas rapidamente pelo golpe de 2016, que então rebaixa as condições da política a vetores reacionários, desmontando um sistema de investimento na cultura e na música. As universidades públicas e os financiamentos públicos são postos na berlinda. A própria noção de cultura e erudição são abominados por líderes e massas de extremadireita. Com isso, prosperam as posições conservadoras e reacionárias, que, na música, polarizam-na nem para o nacionalismo progressista nem para a vanguarda (porque uma é indígena e negra, contra o ideal branco europeu, e a outra é tida por degenerada), mas, sim, para um louvor da música de fundo religioso ou monárquico ou de glória do país ou do ocidente dito judaico-cristão.

No quadro das formas e formações sociais presentes, que fazer politicamente em música? Tendo apontado duas problemáticas sobre 
a formação e uma problemática decisiva sobre a forma, agora aponto seus encaminhamentos políticos críticos. No que tange à formação social brasileira naquele que é o momento presente, impõe-se ao músico contrastar diretamente o regressismo atual. Não retroceder musicalmente ao pretenso "berço natural" teológico-militar-monárquico-conservador de uma música brasileira reputada ocidental cristã branca. No que trata da formação social brasileira enquanto consolidação histórica, é preciso resgatar a música das mãos das pretensões elitistas, que a fazem distinta em face do povo. E, naquilo que se refere à forma na relação entre música e sociedade, impõe-se a tarefa dúplice de avançar pela música e para além dela: tanto a educação enquanto crítica social quanto a vanguarda, a inovação e a superação.

Dado que, estruturalmente, o limite das formas na música é o limite das formas do capitalismo, o problema central é social. Tendo em vista que a reprodução social perpassa a todos os sujeitos com a mesma ideologia capitalista, só é possivel levantar as massas exploradas apontando em vanguarda para a superação social. Em face de tal horizonte, é dúplice a tarefa da música e sua exigência histórica: antecipar na arte a superação das formas musicais e contribuir para formar, socialmente, o povo para a luta superadora desta sociabilidade. $\bigcirc$ complexo social da música é necessariamente político e tem sido demandado, nos dias atuais, a se posicionar tanto pela música quanto pela sociedade. Que os tempos presentes encontrem, na música e nos músicos, atritos críticos contra o regressismo e acordes com a transformação.

São Paulo, 2020.

\section{Dados sobre o autor}

Alysson Leandro Mascaro é Livre-Docente e Doutor em Filosofia e Teoria Geral do Direito pela Faculdade de Direito da Universidade de São Paulo (Largo São Francisco). Professor Associado do mesmo Departamento onde leciona nos cursos de graduação e pós-graduação em direito. Membro do Grupo de Trabalho CLACSO (20 19-2022) Crítica jurídica y conflictos sociopolíticos.

\section{2}

REV. TULHA, RIBEIRÃO PRETO, v. 6, n. 2, pp. -, jul.-dez. 2020 